\title{
9
}

\section{STARCH GRANULE TAPHONOMY:THE RESULTS OF A TWO YEAR FIELD EXPERIMENT}

\author{
Huw Barton \\ School of Archaeology and Ancient History \\ University of Leicester \\ Leicester LE1 7RH United Kingdom \\ Email: hjb15@le.ac.uk
}

\begin{abstract}
This paper reports the results of an experiment designed to investigate the preservation of starch granules on stone tools left exposed and buried in an open field for a total of two years. The study was undertaken to learn in more detail the conditions under which starch granules may be preserved or degraded in the archaeological record, as one of a set of long-term experiments of organic residue preservation. A total of eight stone flakes made from silcrete and silicified tuff were used to process a starchy tuber (sweet potato). Half of the sample was buried and half left on the surface, with samples collected after four months and the remainder after two years. The results indicate that starch granules persist as a residue on stone flakes left on the surface and buried for up to two years and that the physical condition of the starch granules is similar to that encountered in archaeological contexts. An unexpected result of this study was that starch granules appear to have survived in greater numbers on artefacts left on the ground surface, suggesting that rapid burial of tools in the past does not necessarily increase the likelihood of recovering ancient starch granules.
\end{abstract}

\section{KEYWORDS}

starch, taphonomy, sweet potato

\section{INTRODUCTION}

This paper reports the results of an experiment to investigate the preservation of starch granules on stone tools that were exposed or buried in an open field for up to two years. The study was undertaken to simulate the conditions under which starch granules may be preserved or degraded in the archaeological record. While starch granules have now been encountered in a variety of deposits, the mechanism of starch preservation over long timescales is still not well understood.

At the time that this study was initiated in 1993, few taphonomic experiments on the persistence of organic residues had been undertaken and these were solely concerned with the preservation of blood (Brown 1988; Gurfinkel and Franklin 1988), though there is now some published work on organic residue taphonomy (Barton et al. 1998; Jahren et al. 1997; Lu 2003; Therin 1998; Williamson 2006). Starch granules had largely been recovered from tools buried in caves situated in relatively dry environments and from open site middens and caves (Bruier 1976; Hall et al. 1989; Shafer and Holloway 1979; Ugent et al. 1981, 1982). The recovery of starch on stone tools from the Kilu cave, Solomon Islands (Loy et al. 1992), and Balof2, New Ireland (Barton and White 1993) in Melanesia, were early exceptions. Since then the number of studies investigating starch granules has increased dramatically, particularly over the last ten 
years. Starch has been recovered from a wide variety of burial conditions and does not appear to be limited in its preservation by climatic factors (see Barton and Matthews 2006 for a review).

While ancient starch analysis is now accepted by many researchers providing records of tool function, plant use and vegetation history, there is still much to learn about the mechanism(s) of starch preservation. In particular it would be desirable to have a clearer understanding of the rate at which starch granules degrade initially after deposition and to have better knowledge of the characteristics of organic residue deposits that may facilitate long-term preservation of starch granules.

\section{Study area}

The study area was located in the Hunter Valley, approximately 10 kilometres west of the town of Singleton, within the Warkworth Mining Lease, an open cut mine for the extraction of coal (Figure 1). The experimental site lies within a broad valley floor surrounded by low undulating terrain of moderate slope nearby a meander of the Hunter River. Vegetation cover of the study area consisted primarily of tall grasses with some small saplings; a typical Hunter Valley landscape cleared for grazing. The soil consisted of wind and water borne sandy soil from decayed sandstone bedrock, was poor and slightly acidic. A small creek nearby ran intermittently, consisting of a series of contiguous stagnant ponds, some of which were saline.

The location for the experiment was established as part of an ongoing archaeological salvage of areas thought to be adversely affected by construction of a temporary dam across Sandy Hollow Creek, which could lead to local flooding of the area. This study was originally planned as part of a broader taphonomic study undertaken by Laila Haglund (2002) to monitor the post depositional movement of artefacts in Hunter Valley soils.

\section{EXPERIMENTAL AIMS AND METHOD}

This study was originally designed to be one part of a more comprehensive investigation of organic residue taphonomy including stone tools used to work wood, meat and sweet potato. Only the results of the sweet potato are discussed here. This experiment was designed to examine what happens to starch over two time intervals (16 weeks and 108 weeks) and whether there is a difference in the rate of decay/survival of starches on tools that were either buried or left

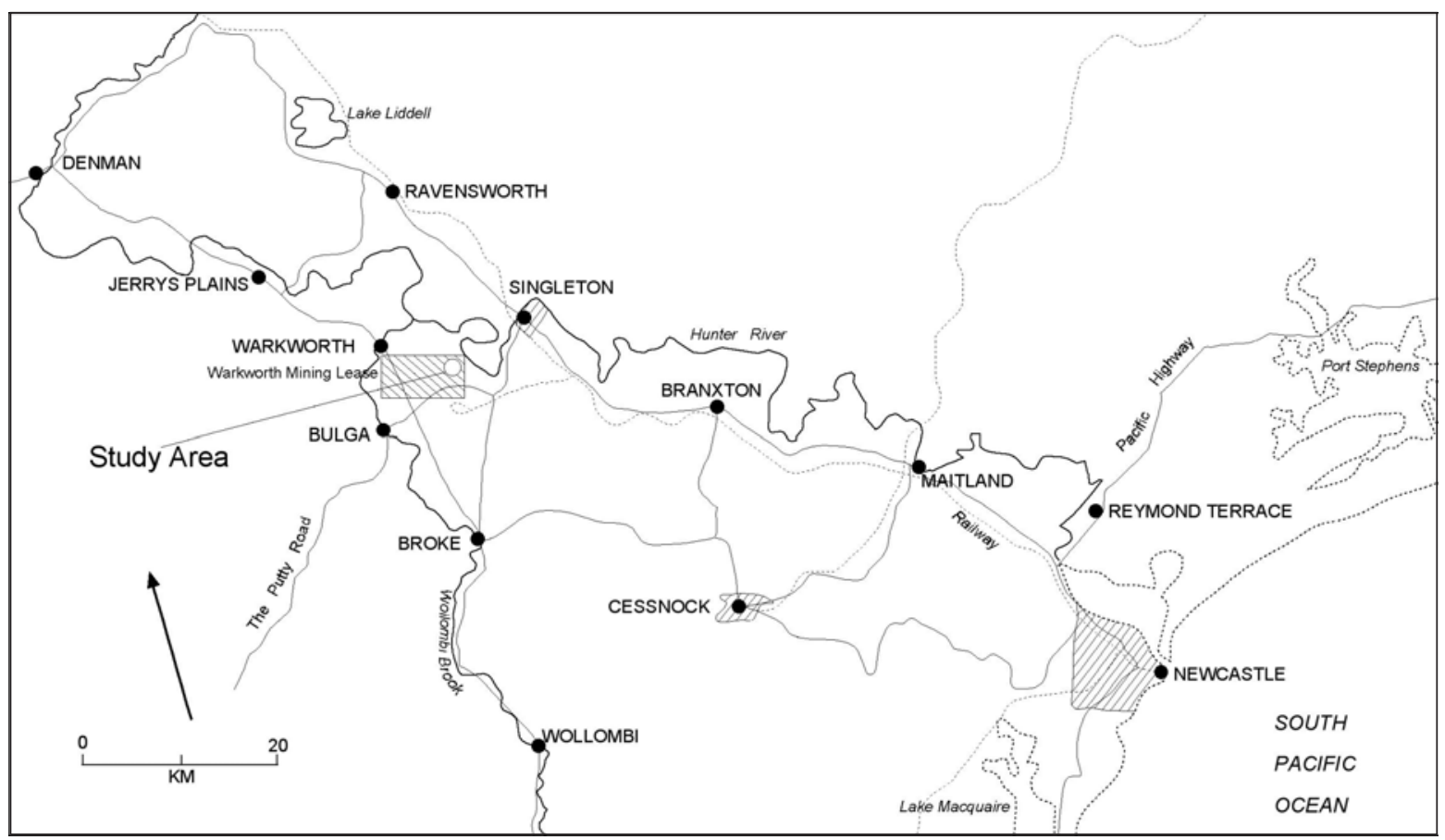

Figure 1. Map of study location. 
on the ground surface. The experiment was initiated in the field on the 20/5/1993 and the final artefacts were collected on the 21/8/1995. The experimental sample was then boxed and remained unanalysed until 2007.

\section{Experimental sample}

The experimental sample consisted of eight artefacts made by the author from locally derived yellow silcrete and silicified tuff, two raw materials commonly used for the manufacture of stone flakes in the region. The experiment was duplicated on each type of raw material, and the sample was then divided into two groups (Group 1 and Group 2), where half of each Group was exposed on the ground surface and half buried. The Group 1 sample was left in the field for a total of 16 weeks (surface and subsurface) and the Group 2 tools for the maximum of 108 weeks (surface and subsurface) before collection. In this way, every combination of raw material, exposure time and exposure conditions were represented.

Each artefact was given a unique number inscribed onto a circular metal tag that was tied to the flake with metal wire (Figure 2). This system proved sufficient for the field study as no tags were detached over the two year period that the experiment was run. Two shallow trenches (one square was for the 16 week sample and the other for the 108 week sample) were excavated for the buried sample. These experimental squares were separated by an intervening distance of two metres. The squares were excavated into the upper A-unit Hunter Valley soils to a maximum depth of between 10 to 20 centimetres.

The artefacts to be buried were laid out on the trench floor with their metal tags raised above ground level and the trench backfilled. The surface sample was then laid out adjacent to the trench on the undisturbed surface (Figure 2). To ensure that these artefacts were not moved by sheet erosion or animals, a plastic mesh (approx $10 \mathrm{~cm}$ square) was laid out over the artefacts and securely pegged around its perimeter. This mesh was not disturbed during the experiment. Soon after being deposited, most of the surface artefacts were attracting the attention of a variety of insects, particularly ants, visibly seen removing surface residues.

At the completion of the experiment, each artefact was placed in a separate clip lock plastic bag and care was taken not to remove adhering sediment from the tool surface. A previous study (Barton et al. 1998) showed that adhering sediment was important in retaining use deposited

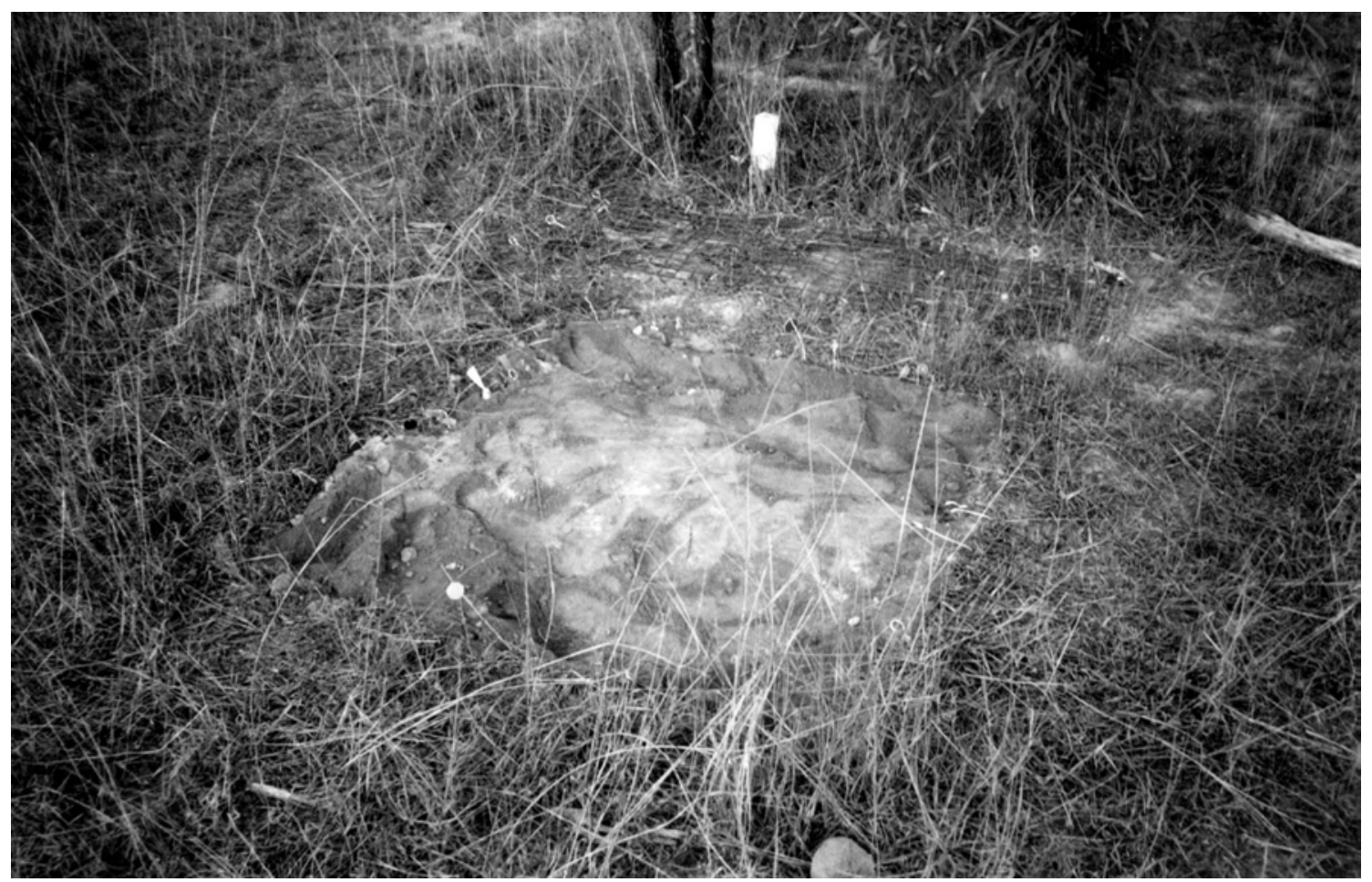

Figure 2. View of experimental area with tagged artefacts on the surface pegged down beneath plastic mesh and buried in test square. 
organic residues. All tools had some sedimentary coating, including those left exposed on the ground surface. The study sample was then stored in plastic bags until 2007.

\section{Microscopy}

All artefacts in the study sample were initially scanned for likely patches of preserved organic matter under low magnification and then in greater detail at high magnification using a Zeiss Axioscop MAT reflected light microscope with X10, X20, X50 and X100 objectives. Identified starch granules were counted and measured. The analysis under transmitted light was undertaken using a Zeiss Axioscop MAT transmitted light microscope with an X63 oil immersion objective. This microscope is also set up for cross polarised and differential interference contrast illumination.

For this experiment, a single aqueous extraction, using ultra pure water and a micropipettor, was applied to the tool surface to remove a sample of residue (see Fullagar 2006 for details and variations of this approach). In this experiment, a 20 microlitre droplet of water was placed on the tool surface and left for approximately 30 seconds then agitated with the nylon pipette tip before retrieving the sediment. The sample was then placed on a glass microscope slide and allowed to air dry under a cover. The mountant used was Naphrax which has a refractive index of 1.73. To ensure that the results between all tools would be comparable, only a single extract per tool was undertaken. However, when dealing with archaeological material, more than one attempt at extraction might be necessary, or even more than one method might be employed, to increase yield or even to achieve a single positive result. A previous study (Barton et al. 1998) successfully undertook whole tool extractions using an ultrasonic bath. However, as further experiments are anticipated with this dataset it was not desirable to remove all residues present at this time.

\section{Sweet potato starch}

The worked material used to simulate tuber use in the past was commercially available sweet potato, Ipomoea batatas, bought in the local supermarket. The starch granules from sweet potato measured for this experiment ranged from three to 23 microns (Table 1). Granule shape is round to sub-round depending on orientation, with single or multiple facets (see Figure 3B). Some granules appear hemispherical when viewed from the side with a clear hilum that is eccentric to highly eccentric. The hilum usually has a distinct vacuole that may be roughly circular or with multiple fissures (see also Horrocks et al. 2004 for a description of archaeological specimens of Ipomoea batatas).

\section{Table 1. Starch granule measurements}

\begin{tabular}{|l|l|l|l|}
\hline & No. of granules measured & Mean $(\boldsymbol{\mu m})$ & Range $(\boldsymbol{\mu m})$ \\
\hline Ipomoea batatas & 105 & 9 & $3.5-23.8$ \\
\hline Tool \# & \multicolumn{3}{|l|}{} \\
\hline $19(\mathrm{~J})$ & 29 & 10.9 & $5.2-15.7$ \\
\hline $5(\mathrm{~K})$ & 39 & 8.1 & $3.2-19.11$ \\
\hline $20(\mathrm{~V})$ & 130 & 6.3 & $3.3-15.5$ \\
\hline $6(\mathrm{Z})$ & 2 & 5.9 & $5.6-6.3$ \\
\hline $7(\mathrm{M})$ & 15 & 8.5 & $4-14.4$ \\
\hline $21(\mathrm{X})$ & 1 & 9.8 & - \\
\hline
\end{tabular}

\section{RESULTS}

All experimental artefacts were recovered at 16 weeks and there was no evidence of disturbance to the experimental area. On inspection after 108 weeks there was some disturbance to the central portion of the square containing the buried sample, though areas at the margins had not been affected. One of the buried artefacts, Tool \#22, was not recovered during final collection. It is most likely that the missing artefact was physically removed either by animal activity or by an overly inquisitive visitor. Several artefacts from the surface sample had become partially buried by sediment from sheet erosion or by local flooding from the nearby creek. 
Within the adhering sediment of all artefacts were high quantities of small rounded, transparent or opaque grains - probably quartz. These grains were typically one to two microns in size and appeared similar in form and had optical properties similar to very small starch granules (Figure 3A). The microscope was not rigged for cross-polarised illumination in reflected light mode so the presence or absence of the extinction cross could not be used for granule identification. Some organic bodies, such as fungal spores which produce a weak cross and otherwise appear starch-like (Haslam 2004; Loy 2006) and the identification of other features, such as a hilum is considered necessary for reliable starch recognition under reflected light.
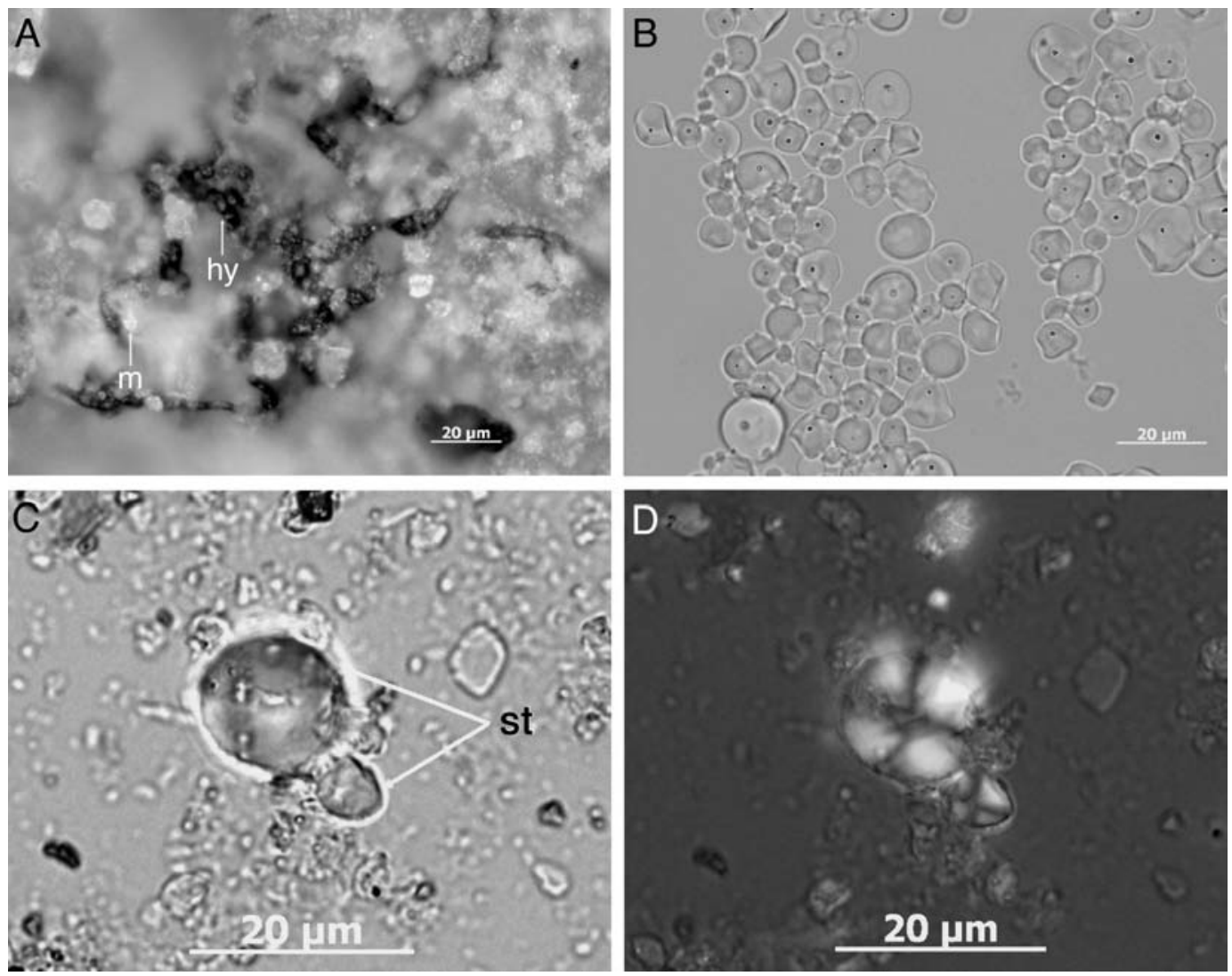

Figure 3. (A) Tool \#7 (108 weeks, surface sample), typical view of tool surface under reflected light observation. Note distribution of fungus (hy) and large numbers of well rounded, bright, mineral grains (m). (B) Ipomoea batatas from modern reference collection. (C) Starch granules (st) extracted from surface of Tool \#7 and also viewed in cross-polaried light (D).

\section{Results from surface tools (Groups 1 and 2)}

The total number of starch granules recovered from the surface sample was 196 compared with 132 granules from the buried sample (Table 2). Contrary to expectations, the results of this experiment reflect a general trend favouring preservation of starch residue on the surface tools; a pattern that is repeated in both Group 1 and Group 2 samples. If we accept these results as reflecting a general trend in residue preservation, the results seem to support early observations made by Loy (1987, 1990; and see also Gurfinkel and Franklin 1988), that rapid drying of residues following their deposition on a tool and the binding of residue with particulate matter in soils may be important factors facilitating long-term preservation (cf. Barton and Matthews 2006). It is not rapid burial itself that is necessarily responsible for residue preservation. Once a residue dries, it forms a hard plaque that may be relatively hydrophobic (Loy 1990:650) and resistant to a wide range of microbial attacks (Barton 2007; Barton and Matthews 2006). Rapid drying and desiccation have also been singled out as common factors in the preservation of other organic compounds over geological as well as archaeological timescales (Eglinton and Logan 1991). The physical scale of the residue might also be an important factor here; where the quantity of residue becomes too small to support a population of microbes. 
Table 2. Starch granule counts from Warkworth experimental tools

\begin{tabular}{|l|l|l|l|l|l|l|}
\hline Tool \# & $\begin{array}{l}\text { Raw } \\
\text { material }\end{array}$ & $\begin{array}{l}\text { Time } \\
\text { (weeks) }\end{array}$ & Location & $\begin{array}{l}\text { Reflected } \\
\text { count§ }\end{array}$ & $\begin{array}{l}\text { Extract } \\
\text { count }\end{array}$ & $\begin{array}{l}\text { Total } \\
\text { g r a } \mathbf{~} \text { u l e } \\
\text { count }\end{array}$ \\
\hline 19 & silcrete & 16 & surface & 7 & 22 & 29 \\
\hline 5 & silicifed tuff & 16 & surface & 0 & 151 & 151 \\
\hline 20 & silcrete & 16 & subsurface & 0 & 130 & 130 \\
\hline 6 & silicified tuff & 16 & subsurface & 0 & 2 & 2 \\
\hline 7 & silicified tuff & 108 & surface & 0 & 15 & 15 \\
\hline 21 & silcrete & 108 & surface & 0 & 1 & 1 \\
\hline 8 & silicified tuff & 108 & subsurface & 0 & 0 & 0 \\
\hline 22 & Silcrete & 108 & subsurface & not recovered & - & - \\
\hline & & Totals & 7 & 321 & 328 \\
\hline
\end{tabular}

$\S$ Reflected refers to counts made directly on the tool surface before extraction to a slide

It might also be concluded that intermittent rewetting following rainfall is not in itself a major mechanism facilitating decay. Rainfall records from the town of Singleton (Figure 1) for the year of 1993 indicate that for the months of May to September, the region received a total of $279 \mathrm{~mm}$ rainfall, an average of $56 \mathrm{~mm} / \mathrm{month}$ (Australian Bureau of Meteorology). Between May 1993 and August 1995 the region received a total of 1,214 mm rainfall. It is probable that water becomes an important factor in organic decay at the microscopic scale only when water acts as a medium for microbes - including fungus and bacteria (Eglinton and Logan 1991:320). Perhaps, when these tools lay on the surface, predominantly dry, in direct sunlight and bathed in ultraviolet radiation, this did actually aid in the long-term preservation of organic matter at the microscopic scale.

\section{Results from buried tools (Groups 1 and 2)}

A total of 132 starch granules were recovered from the buried sample. All of these were from Group 1 tools. Survival of starch in a buried context appears highly variable, and in this context at least, likely to result in one tool out of three having very low counts or possibly no starch residues at all. No starch granules were recovered from Group 2 sub-surface sample that were left for 108 weeks in the field. Starch granules appear to have been removed from tool surfaces at a far greater rate in the buried experimental sample than in the surface sample; where in fact the reverse had been anticipated. It was thought that constant exposure to the elements would be far more likely to remove starch from these tools via various weathering processes and in particular the constant re-wetting from rain.

The buried tools lay at a relatively shallow depth of $10-20 \mathrm{~cm}$ in what was essentially a loosely packed and recently disturbed soil horizon. It is possible that this soil was biologically very active throughout the experiment and at this depth would have contained primarily aerobic microorganisms, such as fungi. In fact, nearly all tools analysed (buried and surface samples) had traces of fungal activity on the tool surface in the form of hyphal filaments (Figure 3A). Some of these filaments had infested masses of starch granules, e.g. Tool \#5 (Group 1: surface, Figure 4C) and cellulose tissue, Tool \#7 (Group 2: surface). The high starch counts from Tool \#20 indicate that in the right conditions, starch will be well preserved, even after 16 weeks burial in biologically active soils. The results from the sample left for 108 weeks is within the expected range for starch granules encountered in archaeological contexts (see above).

For reasons stated above, it was thought that preservation would be more likely on buried tools enclosed in soil than on tools exposed to the elements at the ground surface. We should be cautious not to over analyse this trend as there is considerable variation between individual tools. For example, Tool \#19 from the surface had 29 granules whereas one of the buried tools, Tool \#20 had a count of 130 granules and Tool \#6 had a total count of only two granules. These results might reflect a wider range of variation between individual tools than is catered for in this 

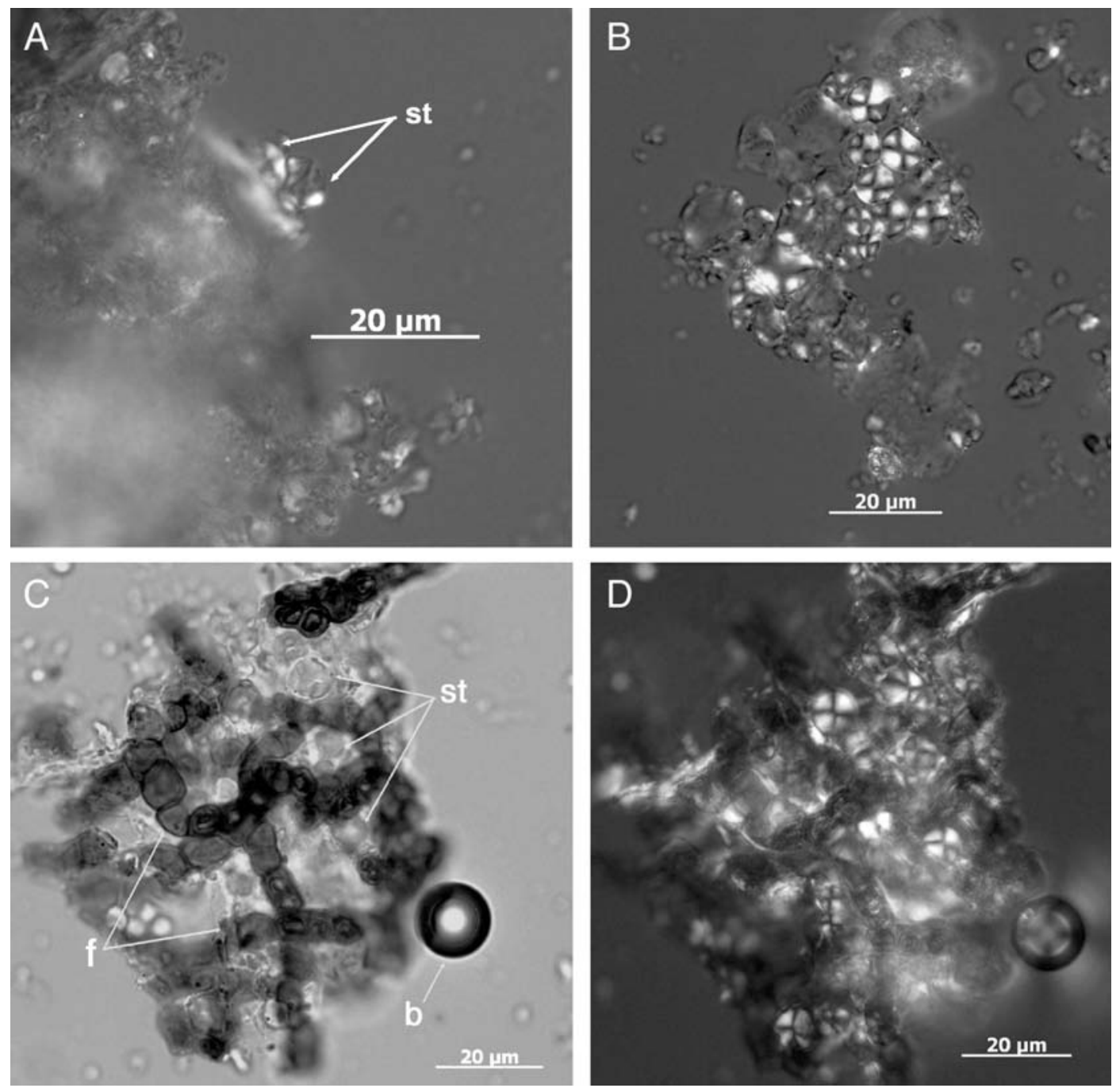

Figure 4. (A) Starch granules (st) from Tool \#6 viewed in cross-polarised light. (B) Mass aggregation of granules from Tool \#20. (C) Mass aggregation of starch granules (st) surrounded by fungal bodies (f). (D) Same view as $\mathrm{C}$ but in cross-polarised light.

experiment and that in fact there appears to be little difference in the nature of starch degradation when tools are buried or left on the surface over a period of 16 weeks.

\section{Granule frequency}

A total of 328 starch granules were recovered from the surface and subsurface tools in this experiment, which includes counts from reflected light observations of the tool edges and the single aqueous extraction from the tool surface. The aqueous extractions targeted those areas identified to have the most abundant starch residues on the tool. A total of 312 granules were recorded from the 16 week sample (Group 1), which included surface and subsurface tools, and a total of 16 granules were recorded in the 108 week tool sample (Group 2). This represents a large variation in starch counts between these two samples. No sample was initially taken at the time the tools were deposited, but it might be assumed that initial sampling would recover many hundreds if not thousands of granules. Only a single extraction was taken at one spot on the tool; multiple samples would be expected to increase counts in both experimental groups.

The overall trend is clear; a substantial removal of starch from all tools occurs relatively soon after deposition. A further sample of artefacts selectively analysed in a series of time intervals would confirm if this decay path is exponential as found with other studies of organic decay (e.g. Haslam 2004:1721). The recovery rates of starch from the 108 week sample are already representative of the types of counts likely to be encountered in many archaeological contexts (e.g. Barton 1998, 2005; Cosgrove et al. 2007; Pearsall et al. 2004; Perry 2004, Piperno et al. 
2000; Piperno et al. 2004) with single to frequently less than 100 granules recovered per tool; though the method of extraction is an important factor here. Variation in the numbers of recovered granules from each tool in surface and subsurface contexts is very high, possibly reflecting smallscale processes affecting organic preservation at the scale of each tool. To generate enough data for reasonable statistical observations to be made a far larger experimental sample than this one would be necessary (see Haslam, this volume).

\section{Physical properties of the starch granules}

An important aspect of this study is that it provides an opportunity to view the physical condition of starch granules exposed to two different depositional contexts. Starch has been shown to remain in good physical condition for up to 100 years when kept as dried tuber or processed flour (Barton 2007). That study also showed that starch had retained the biochemical and physical properties of modern starch, though in some cases granules had been slightly altered internally, as indicated by poorer birefringence and a disjointed extinction cross (Barton 2007). The starch granules from this study show a range of physical alterations and in some cases provide some clues as to the mechanism(s) that may have aided their preservation.

Granules from all tools generally occur in good condition (Figure 3C) but some display a range of physical alterations including cracking (Figure 5A and B), complete breaks fragmenting the granule, and a degraded or fuzzy extinction cross (Figure 3D). As found in a previous study (Barton 2007) some starch granules from a single artefact may appear in very good condition while others from the same sample may be partially or badly degraded. I argued that this may have resulted from differential preservation of the starches within a single residue deposit on a tool surface. Some granules may lie in situations close to or near the surface of a residue and thus be available to attack by microorganisms whereas other granules may be sealed within the residue and shielded from biological decay.

Granules enclosed in sediment were common in this study. In some cases granules appeared, when slide mounted, to be partially surrounded by very small particulates (e.g. Figure 5, B-D). Sometimes the granule appeared fully enclosed, as shown in Figure 5, C-D. It is suggested that this sediment layer may be enough to prevent microbes attacking starch granules forming a protective barrier around the granule. This observation is what would be expected if Particulate Organic Matters (POMs) also play a role in organic preservation of residues at the micro scale (see Barton and Matthews 2006, Golchin et al. 1998, Waters and Oades 1991). This shield of micro-particulates is likely an important aspect of a general mechanism of long-term organic preservation of all residues, not just starch granules (see figures in Piperno and Holst (1998) for similar examples of starch granules surrounded by small particulate matter).

Given that organic breakdown and decay in soils is argued to be relatively rapid, occurring over timescales of days rather than months (see Haslam 2004), unless some other process can retard either microbial activity or chemical breakdown, the persistence of starch after two years is counter to many general expectations of organic decay.

Phytoliths were present on several tools. The dumbbell form was most common and is associated with grasses (Piperno 2006). Given the depositional context within a grassed paddock, this is highly unsurprising - but again indicates caution with any interpretation of adhering matter on a tool surface. The presence of organics alone (especially isolated occurrences) only indicates the presence of organic matter in the deposit, not the presence of a use-derived residue. For each tool a contextual case must be made as to why this adhering matter was or was not derived from its use.

\section{CONCLUSIONS}

Starch granules were documented on six of the seven artefacts used for this study; the eighth piece could not be found at the conclusion of the experiment. This experiment confirms that modern starch granules can survive up to 108 weeks in an open field site, subject to the attentions of 

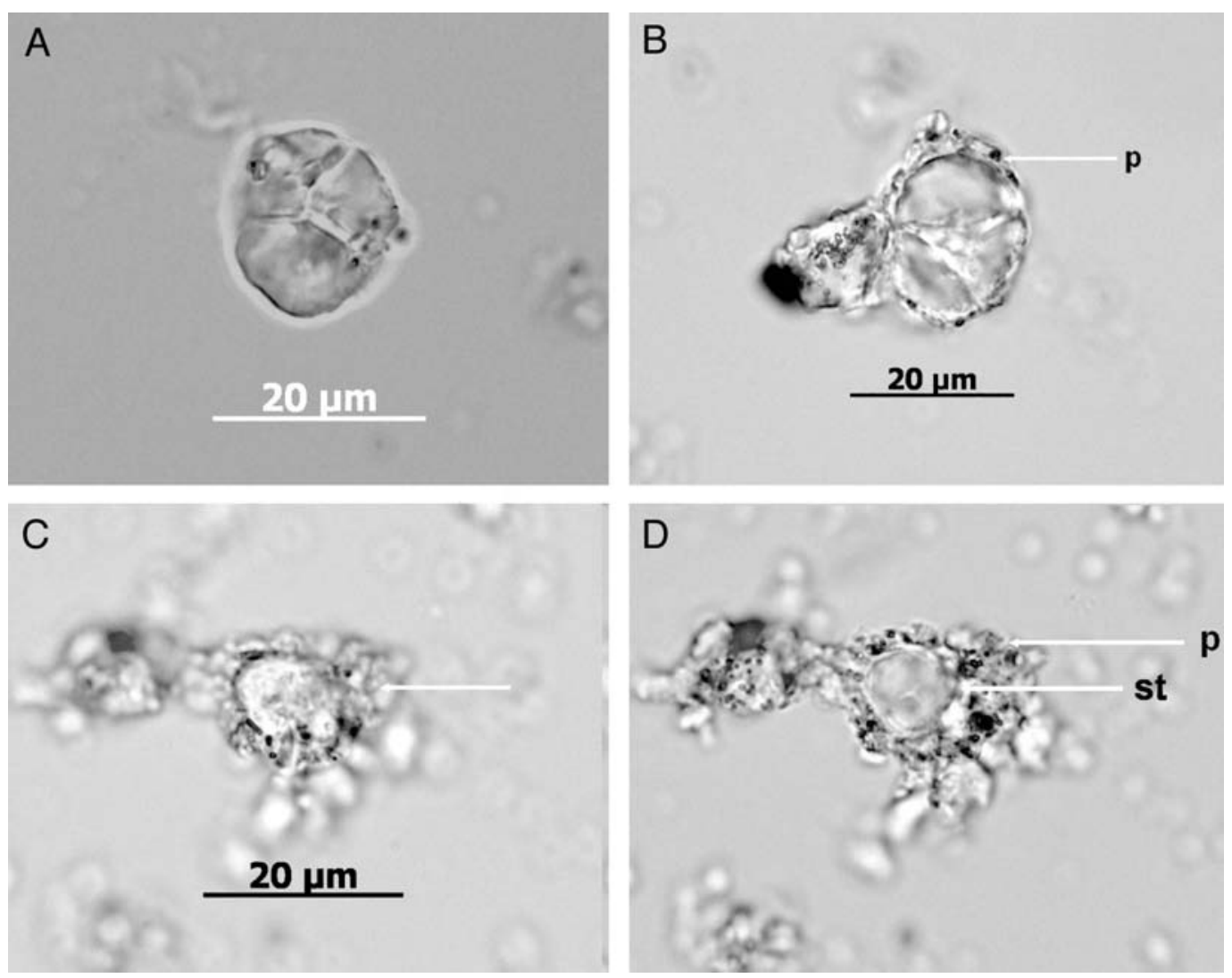

Figure 5. (A) Damaged starch granule from Tool \#19 (4 months, surface sample). (B) Damaged starch granule from Tool \#5 (4 months, subsurface sample), cracked and surrounded by particulate matter (p). (C) and (D) consecutive views of starch granule from Tool \#20 (4 months, subsurface sample) completely encased in particulate matter (p). View in $\mathbf{C}$ focussed on top of encased granule (indicated by arrow) and view in $\mathbf{D}$ after focussing downwards into the object, revealing starch granule (st) within.

the meso-fauna (ants in particular) and micro-fauna (fungi were visible on nearly all recovered artefacts). Recovery rates from a single aqueous extract range from two granules to 151 granules. Preservation is variable for each artefact, suggesting that the nature of preservation may be peculiar to each piece, even within the same soil matrix.

A major finding was the discovery that tools left on the surface apparently had far better starch preservation than those buried in the A-horizon soils. This was unexpected (though see Haslam 2004 for a counter view) as I had anticipated that the act of burial would provide a more secure environment for long-term starch preservation (e.g Lu 2003). However, these tools were buried at shallow depth, between 10 to $20 \mathrm{~cm}$, well within the upper organic-rich and well aerated soil layer where the activity of microorganisms would be high (Barton and Mathews 2006:79$83)$.

Further experiments with starch granules will help us understand the complex nature of organic preservation at the microscopic scale and are essential if we are to fully understand the mechanisms and conditions of organic residue preservation. The results of this and other experiments reveal the complexities of residue formation but should increase confidence in the utility of this class of archaeological information to make important contributions to current scholarship.

\section{ACKNOWLEDGEMENTS}

I would most like to thank Dr Laila Haglund for her enormous patience waiting for the results of this study to actually come to light in a publication and for allowing me to participate in her 
own experimental program. I would also like to thank Warkworth Mining Limited for permission to undertake the work on lands under their management. The Mine Management, and notably their environmental and geological staff, was very helpful with advice and in ensuring that the experimental location remained as undisturbed as possible. The project was initiated when the author was working in contract archaeology but all analyses were carried out while funded by the Wellcome Trust at the University of Leicester, UK.

\section{REFERENCES}

Barton, H. 2005. The case for rainforest foragers: the starch record at Niah Cave, Sarawak. Asian Perspectives 44:56-72.

Barton, H. 2007. Starch residues on museum artefacts. Journal of Archaeological Science 34: $1752-1762$.

Barton, H. and P.J. Matthews 2006. Taphonomy. In R.Torrence and H. Barton (eds) Ancient Starch Research, pp.75-94. Walnut Creek: Left Coast Press Inc.

Barton, H., Torrence, R., and Fullagar, R. 1998. Clues to stone tool function re-examined: comparing starch grain frequencies on used and unused obsidian artefacts. Journal of Archaeological Science 25: 1231-1238.

Barton, H. and J.P. White 1993. Use of stone and shell artefacts at Balof 2, New Ireland, Papua New Guinea. Asian Perspectives 32: 169-181.

Brown, P. 1988. Residue analysis of stone artefacts from Yombon, West New Britain. BA Hons Thesis. Department of Anthropology, University of Sydney.

Bruier, F.L. 1976. New clues to stone tool function: plant and animal residues. American Antiquity 41: 478-484.

Cosgrove, R., J. Field and A. Ferrier 2007. Environmental history of the humid tropics region of north-east Australia: the archaeology of Australia's tropical rainforests. Palaeogeography, Palaeoclimatology, Palaeoecology 251: 150-173.

Eglinton, G and G.A. Logan,1991. Molecular preservation. Philosophical Transactions of the Royal Society of London B 333: 315-328.

Fullagar, R. 2006. Starch on artefacts. In R.Torrence and H. Barton (eds) Ancient Starch Research, pp.177-203. Walnut Creek: Left Coast Press Inc.

Golchin, A., A.J.Baldock and J.M. Oades 1998. A model linking organic matter decomposition, chemistry, and aggregate dynamics. In R.Lal, J.M. Kimble, R.F. Follett and B.A. Stewart (eds) Soil Processes and the Carbon Cycle, pp.245-266. New York: CRC Press.

Gurfinkel, D.M. and U.M. Franklin 1988. A study of feasibility of detecting blood residues on artefacts. Journal of Archaeological Science 15: 83-97.

Haglund, L. 2002. Archaeological Investigations within Warkworth Mining Lease: Aboriginal Sites along Sandy Hollow Creek, NSW. Vol.V: Taphonomic experiments and observations. Report to Warkworth Mining Limited, Haglund and Associates.

Hall, J., S. Higgins and R. Fullagar 1989. Plant residues on stone tools. In W.Beck, A.Clarke and L. Head, (eds) Plants in Australian Archaeology, pp.136-160. St Lucia: University of Queensland, Tempus 1. 
Haslam, M. 2004. The decomposition of starch grains in soils: implications for archaeological residue analyses. Journal of Archaeological Science 31: 1715-1734.

Horrocks, M., G. Irwin, M. Jones and D. Sutton 2004. Starch grains and xylem cells of sweet potato (Ipomoea batatas) and bracken (Pteridium esculentum) in archaeological deposits from northern New Zealand. Journal of Archaeological Science 31: 251-258.

Jahren, A. H., N. Toth, K. Schick, J.D. Clark and R.G. Amundson 1997. Determining stone tool use: chemical and morhpological analyses of residues on exprimentally manufactured stone tools. Journal of Archaeological Science 24: 245-250.

Loy, T.H. 1987. Recent advances in blood residue analysis. In W.R. Ambrose and J.M.J. Mummery (eds) Archaeometry: Further Australasian studies, pp.57-65. Canberra: Australian National University.

Loy, T.H. 1990. Prehistoric organic residues: recent advances in identification, dating, and their antiquity. In E. Pernicka (ed.), Archaeometry '90, pp.645-656. Basel and Boston: Springer Verlag.

Loy, T.H. 2006. Optical properties of potential look-alikes. In R.Torrence and H. Barton (eds) Ancient Starch Research, pp.123-124. Walnut Creek: Left Coast Press Inc.

Loy, T.H., M. Spriggs and S. Wickler 1992. Direct evidence for human use of plants 28,000 years ago: starch residues on stone artefacts from the northern Solomon Islands. Antiquity 66: 898-912.

Lu, T. 2003. The survival of starch in a subtropical environment. In D.M. Hart and L.A. Wallis (eds), Phytolith and Starch Research in the Australasian-Pacific-Asian Regions: The State of the Art, pp.119-126. Terra Australis 19. Canberra: Pandanus Books.

Pearsall, D.M., K.Chandler-Ezell and J.A. Zeidler 2004. Maize in ancient Ecuador: results from residue analysis of stone tools from the Real Alto site. Journal of Archaeologcial Science 31: $423-442$

Perry, L. 2004. Starch analyses reveal the relationship between tool type and function: an example from the Orinoco valley of Venezuela. Journal of Archaeological Science 31: 1069-1081.

Piperno, D.R. and I. Holst 1998. The presence of starch granules on prehistoric tools from the humid Neotropics: indicators of early tuber use and agriculture in Panama. Journal of Archaeological Science 25: 765-776.

Piperno, D.R., A.J. Ranere, I. Holst and P. Hansell 2000. Starch granules reveal early root crop horticulture in the Panamanian tropical forest. Nature 407: 894-897.

Piperno, D.R. 2006. Phytoliths. A Comprehensive Guide for Archaeologists and Paleoecologists. Oxford: AltaMira Press.

Piperno, D.R., I. Weiss, I. Holst, and D. Nadel 2004. Processing wild cereal grasses in the Upper Palaeolithic revealed by starch grain analysis. Nature 430: 670-673.

Shafer, H.J. and R.G. Holloway 1979. Organic residue analysis in determining stone tool function. In B. Hayden, (ed.) Lithic Use-wear Analysis, pp.385-399. London: Academic Press.

Therin, M. 1998. The movement of starch grains in sediments. In Fullagar, R. (Ed.) A Closer Look: Recent Australian Studies of Stone Tools, pp.61-72. Sydney: Sydney University Archaeological Methods Series 6. 
Ugent, D., S. Pozorski and T. Pozorski 1981. Prehistoric remains of the sweet potato from the Casma Valley of Peru. Phytologia 49: 401-415.

Ugent, D., S. Pozorski and T. Pozorski 1982. Archaeological potato tuber remains from the Casma Valley of Peru. Economic Botany 36: 182-192.

Waters, A.G. and J.M. Oades 1991. Organic matter in water-stable aggregates. In W.S. Wilson (ed.), Advances in Soil Organic Matter Research: The Impact on Agriculture and the Environment, pp.163-174. Cambridge: Royal Society of Chemistry.

Williamson, B. 2006. Investigation of potential contamination on stone tools. In R.Torrence and H. Barton (eds) Ancient Starch Research, pp.89-90. Walnut Creek: Left Coast Press Inc. 